\title{
Falsche Signale
}

\section{Liebe Leserin, lieber Leser,}

nun ist es soweit: Nach vielen Jahren der Diskussion, wie man Elektromobilität im Rahmen der Energiewende gesellschaftlich und marktpolitisch etablieren kann, subventioniert die Bundesregierung den Kauf von E-Autos. Damit folgt Deutschland europäischen Ländern, in denen der Markthochlauf längst gelungen ist.

Seit Mai erhält der Käufer eines Elektroautos in Deutschland eine staatliche Prämie von 4000 Euro, jedes neue Plug-inHybrid-Fahrzeug wird mit 3000 Euro gefördert. Die Förderung ist auf 1,2 Milliarden Euro begrenzt. Die Hälfte davon tragen die Automobilhersteller. Zusätzlich fließen Investitionen in den Ausbau der öffentlichen Ladeinfrastruktur im Rahmen von 300 Millionen Euro, von 2017 bis 2020. Die Schnellladeinfrastruktur wird mit 200 Millionen Euro bedacht, konventionelle Ladesäulen will man mit 100 Millionen Euro fördern.

Die Verhältnismäßigkeit der Mittel stimmt hier nicht, weder in der Förderung der unterschiedlichen Antriebstechnik sowie in der Art und Weise, die Infrastruktur aufzubauen, noch in der Gewichtung der beiden Disziplinen. Es ist beispielsweise fraglich, ob Plug-in-Fahrzeuge in ihrer derzeitigen elektrischen Ausbaustufe überhaupt als Elektrofahrzeuge klassifiziert werden sollten. Mit einer Differenz von lediglich tausend Euro zu Elektrofahrzeugen fördert die Regierung große SUVs, denen die Technik in erster Linie hilft, die Flottenverbräuche des NEFZ und WLTP einzuhalten - und das mit einem zu hoch angesetzten elektrischen Fahranteil. Dies führt wieder einmal zu unrealistischen Kraftstoffverbrauchsangaben. Bei einigen Fahrzeugen, die unserer Redaktion zum Test zur Verfügung gestellt wurden, erzielten wir im Durchschnitt nicht die angegebenen $50 \mathrm{~km}$ elektrische Reichweite, sondern nur 35 km - und das bei besten Randbedingungen und trickreichen energie- sparenden Fahrstrategien. 2,1 l auf $100 \mathrm{~km}$ ? Das ist unrealistisch. Erneut verpasst die Branche die Möglichkeit, die Kunden mit praxisnahen Angaben für sich zu gewinnen. Noch schwerer wiegt das schwindende Vertrauen, denn die geweckten Erwartungen an elektrisches Fahren werden wieder mal enttäuscht.

Mit batterieelektrischen Fahrzeugen, also den wirklichen E-Autos, lassen sich realistische Reichweiten von immerhin $150 \mathrm{~km}$ erfahren, Tendenz steigend. Doch auch hier muss man um Glaubwürdigkeit und Vertrauen kämpfen. Ein dichteres Netz von Ladestationen würde die Debatte um Reichweiten deutlich entspannen. Hier wurden ebenfalls falsche Signale seitens der Bundesregierung gesetzt. Die teuere Schnellladetechnik gilt es mehr zu fördern. Hier verpuffen die 200 Millionen Euro.

E-Mobilität lässt sich effektiver forcieren: nämlich mit dem Ausbau der Infrastruktur. Das sinnlose Warten auf Perfektion und Rekordreichweiten sowie die Superbatterie wären ad absurdum geführt.

Beste Grüße,

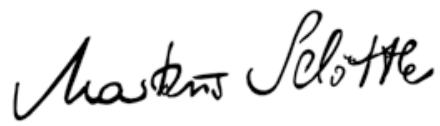

Markus Schöttle

Stellvertretender Chefredakteur

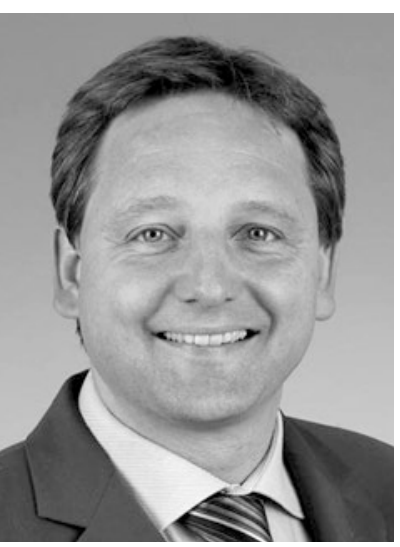

TГГech

Ensuring Reliable Networks

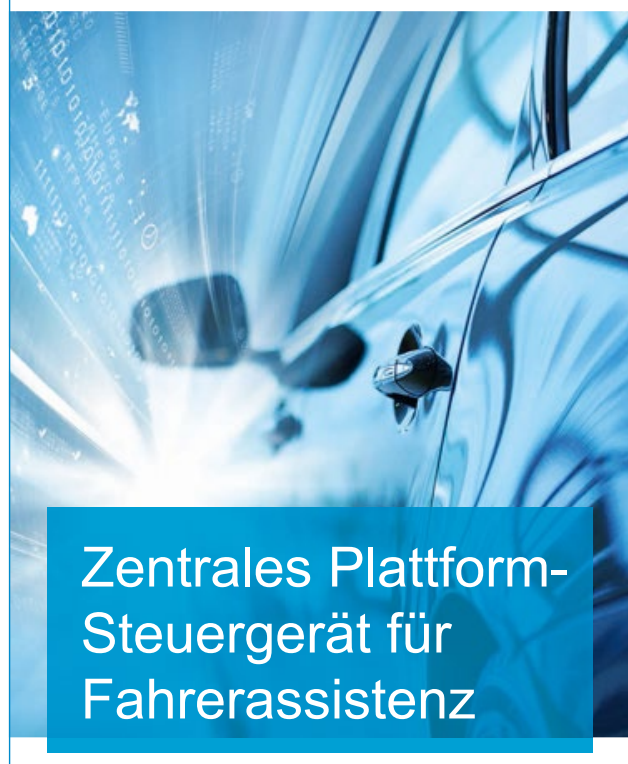

\section{TTA Drive}

- Hochintegration verschiedener Assistenzsysteme auf einer Plattform

- Ethernet-basierte On-board-Vernetzung sicherheitsrelevanter Fahrfunktionen

- Bestmögliche Objekterkennung dank sensorübergreifender Datenfusion

- Skalierbare Architektur

- Zentrale Diagnose aller Systeme

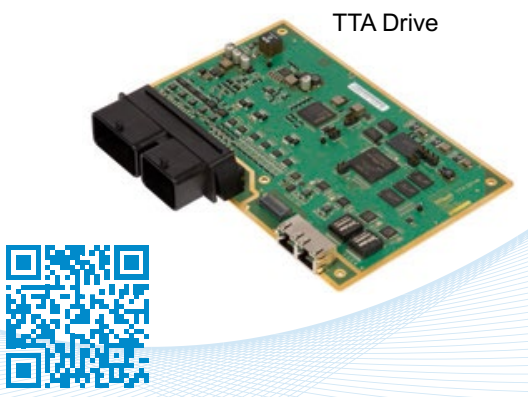

products@tttech-automotive.com

www.tttech.com/ TTTech-ADAS 